\title{
Proteomic analysis of proteins expressed by Helicobacter pylori under oxidative stress
}

\author{
Ming-Hong Chuang ${ }^{*}{ }^{*}$, Ming-Shiang $\mathrm{Wu}^{2 *}$, Jou-Town Lin $^{2}$ and Shyh-Horng Chiou ${ }^{1,3}$ \\ ${ }^{1}$ Institute of Biochemical Sciences, National Taiwan University, Taipei, Taiwan \\ 2 Division of Gastroenterology, Department of Internal Medicine, National Taiwan University Hospital, \\ Taipei, Taiwan \\ ${ }^{3}$ Institute of Biological Chemistry, Academie, Taipei, Taiwan
}

Helicobacter pylori is a spiral, slow growing gram-negative microaerophilic bacterium. It has been shown to be the etiological agent of gastroduodenal diseases, such as chronic gastritis, gastric and duodenal ulcers, and gastric cancer. To address the influence of oxidative stress and its underlying mechanisms, we have compared proliferation, urease activity and protein expression profile of $H$. pylori incubated under normal microaerophilic $\left(5 \% \mathrm{O}_{2}\right)$ and aerobic stress $\left(20 \% \mathrm{O}_{2}\right)$ conditions. Oxidative-stress cells displayed coccoid morphology and time-dependent decrease in proliferation. The urease activity was completely abrogated after $32 \mathrm{~h}$. We have further compared the protein expression profiles of $H$. pylori under normal growing and oxidative-stress conditions by a global proteomic analysis, which includes high-resolution 2-DE followed by MALDI-TOF-MS and bioinformatic databases search/peptide-mass comparison. The results revealed that more than ten proteins were differentially expressed under oxidative stress. Most notably, the protein expression levels of urease accessory protein E (UreE, an essential metallochaperone for urease activity) and alkylhydroperoxide reductase $(\mathrm{AhpC})$ with antioxidant potential are greatly decreased under stress conditions. Measurements of messenger RNA transcription level by performing RT-PCR on total mRNA also confirmed that gene expressions for these two proteins are consistently repressed under oxygen tension. These changes form a firm basis to account for the loss of urease activity and anti-oxidative ability of $H$. pylori after long-term exposure to reactive oxygen. Conceivably, UreE and AhpC may thus be listed as potential targets for the development of therapeutic drugs against H. pylori.

Keywords: Alkylhydroperoxide reductase / Helicobacter pylori / Oxidative stress / 2-DE/ MS / Urease accessory protein E

\section{Introduction}

The discovery and successful culture of H. pylori, a gramnegative, spiral and microaerophilic bacterium has revolutionized the diagnosis and treatment of gastroduodenal diseases [1-3]. Epidemiological studies suggested that about one half of the world adult population may harbor this bacterium in stomachs $[4,5]$. Previous reports have suggested that to survive the highly acidic medium of stomach, H. pylori colonies can

Correspondence: Dr. Shyh-Horng Chiou, Institute of Biochemical Sciences, National Taiwan University, Taipei, 10617, Taiwan E-mail: shchiou@gate.sinica.edu.tw Fax: +886-2-23635038

Abbreviations: AhpC, alkylhydroperoxide reductase; CFU, colony-forming unit; UreE, urease accessory protein $\mathrm{E}$
Received: September 3, 2004

Revised: November 20, 2004

Accepted: December 29, 2004 release ammonia from urea by urease of the microorganism, thereby neutralizing the gastric acid in stomach [6, 7]. However, ammonia is also a toxic substance to epithelial cells, so that its production plus other factors may often induce inflammation on epithelial cells [8-10]. Therefore, prolonged infection and inflammation due to persistent $H$. pylori colonization usually lead to chronic gastritis, peptic ulcer and gastric malignancies such as adenocarcinomas of the stomach [11].

The variable clinical outcomes of $H$. pylori infection probably result from different severity and distribution of $H$. pylori-induced gastric inflammation. Recent studies have suggested some correlation between the protection of host cells against $H$. pylori infection and stress-induced protein factors including heat shock proteins [12-14]. Among all

\footnotetext{
* These authors contributed equally.
} 
contributing factors related to inflammation, the oxidative stress has been assumed to be one of the key determinants leading to the pathogenesis of gastric inflammation. Such oxidative stress may also exert bi-directional effects on hosts and pathogens. The H. pylori-induced oxidative stress can cause lesions in host cells, whereas H. pylori will also face the attack of oxygen-related free radicals released from phagocytes of the infected host [15]. To survive the toxic reactive oxygen species released by the host, $H$. pylori must possess some defensive mechanisms to protect against oxidative stress. The importance of oxidative stress on $H$. pylori is illustrated by the observation that $H$. pylori will transform from the bacillary form to the coccoid form, and show marked decrease of proliferation potential under oxygen tension in cultures in vitro or in environment outside the stomach in less than 1 day $[16,17]$.

It has been documented that the optimal range of oxygen concentration for the growth of $H$. pylori is $5-10 \%$. Hence, the majority of current cultured strains of H. pylori are from clinical biopsies of human stomachs rather than the natural environment in which the oxygen tension $\left(20 \% \mathrm{O}_{2}\right)$ is not suitable for long-term survival of $H$. pylori. Therefore, $H$. pylori may have a protective mechanism to survive the shortterm oxygen shock but not long-term oxidative stress. Previous reports have demonstrated that $H$. pylori could combat the oxidative stress and reduce toxic and reactive peroxide radicals by alkylhydroperoxide reductase (AhpC), NapA, catalase and NADPH quinone reductase [18-20]. However, the overall response and detailed mechanism for $H$. pylori to overcome oxidative stress remains ill defined.

Proteomes depict snapshots of protein compositions of particular cells or tissues at defined time points. Through the assistance of constantly increasing databases of complete genomes from various model organisms including $H$. pylori [21], proteomes of any samples from some exotic biological sources can now be educible at protein expression levels by 2-DE coupled with MALDI-TOF-MS regarding their protein identities in relation to other known protein sequences deposited in various databanks. To date, oxidative-stress-related proteome changes in $H$. pylori-infected human gastric mucosa have been studied by proteomic approaches [22], but no such efforts have been reported on protein changes of $H$. pylori under different oxidative stresses. In this study, our objective was to apply the powerful holistic proteomic approach to characterize and compare protein expression profiles of $H$. pylori under normal and hyperoxia conditions.

\section{Materials and methods}

\subsection{Bacterial strains and growth conditions}

Three H. pylori strains, ATCC 43504 and two clinical isolates (HD30 and HC28), were used. The clinical isolates were obtained from gastric biopsy specimens from patients with duodenal ulcer (HD30) and gastric cancer (HC28). $H$. pylori were grown on CDC anaerobe blood agar plates (BD) at $37^{\circ} \mathrm{C}$ in modular atmosphere controlled system $\left(5 \% \mathrm{O}_{2}\right.$, $10 \% \mathrm{CO}_{2}$, and $85 \% \mathrm{~N}_{2}$ ) (DU Scientific). All strains were confirmed to be $H$. pylori because of the presence of urease activity and the helical morphology of these organisms observed by phase-contrast microscopy. Cultured cells were washed with PBS buffer ( $\mathrm{pH} 7.4)$ and used for experiments.

\subsection{Time-course analyses of oxidative stress on cell proliferation and urease activity}

Standard strains and clinical isolates of $H$. pylori were grown on CDC plates under normal condition $\left(5 \% \mathrm{O}_{2}\right)$ for $48 \mathrm{~h}$, and then were transferred to incubator under atmospheric oxygen condition $\left(20 \% \mathrm{O}_{2}\right)$ for $8-36 \mathrm{~h}$. Before performing assays, harvested samples from appropriate intervals were quantified by measuring $\mathrm{OD}_{600}$ values. The urease activity of each strain was determined by a urease assay kit (Biostar) according to the instructions of the manufacturer. The standard urease activity of $H$. pylori growing under microaerobic condition $\left(5 \% \mathrm{O}_{2}\right)$ was designated as $100 \%$. The cell proliferation assay was conducted by subculturing each test strain to fresh plates after stress treatment for $8-36 \mathrm{~h}$. The number of living cells was determined and represented as colony-forming unit (CFU) [23].

\subsection{2-DE and image analysis}

Cell pellets of $H$. pylori $\left(1 \times 10^{7}\right.$ cells) were solubilized in lysis buffer containing $8 \mathrm{~m}$ urea, $0.5 \%$ CHAPS or Triton X100 , After sonication, about $300 \mu \mathrm{g}$ total protein was loaded onto IPG gel strips $(\mathrm{pH} 3-10,18 \mathrm{~cm}$, Amersham Pharmacia Biotech.). The IPG strips were rehydrated overnight according to the operational guideline (Amersham). For the first-dimensional separation, IEF was carried out using the Multiphor II system (Amersham Pharmacia Biotech.) at $20^{\circ} \mathrm{C}$ with $50-3500 \mathrm{~V}$ for $19 \mathrm{~h}$. After IEF, the IPG strips were equilibrated for $10 \mathrm{~min}$ each in the equilibration solution $(50 \mathrm{~mm}$ Tris- $\mathrm{HCl}, \mathrm{pH} 8.8,6 \mathrm{~m}$ urea, 2\% SDS, 30\% glycerol, $100 \mathrm{mg}$ DTT and $750 \mathrm{mg}$ IAA, respectively), attached to the $15 \%$ SDS-polyacrylamide gel, then covered by $0.5 \%$ agarose gel. 2 -DE was conducted at $130-250 \mathrm{~V}$ for $5-6 \mathrm{~h}$ until the bromophenol blue reached the bottom of the gel. The gels were fixed in 10\% TCA and stained in CBB-G250 stain overnight. The protein patterns in the gels were scanned and recorded as digitalized images using a high-resolution scanner (Epson Perfection 1270), then analyzed using ImageMasterTM 2D Elite version 3.10 software (Amersham Pharmacia Biotech) to automatically detect and quantify protein spots. Intensity levels were normalized between gels as a proportion of the total protein intensity detected for the entire gel. 


\subsection{In-gel digestion and MALDI-TOF-MS}

Based on the 2-D gel analysis of samples under different oxygen conditions, differentially expressed proteins were selected for further identification by MS. These spots were cut from 2-D gels, then destained three times with $25 \mathrm{~mm}$ ammonium bicarbonate buffer ( $\mathrm{pH} 8.0$ ) in $50 \%$ ACN for $1 \mathrm{~h}$. The gel pieces were dehydrated in $100 \%$ ACN for $5 \mathrm{~min}$ and then dried for $30 \mathrm{~min}$ in a vacuum centrifuge. Enzyme digestion was performed by adding $0.5 \mu \mathrm{g}$ trypsin in $25 \mathrm{~mm}$ ammonium bicarbonate per sample at $37^{\circ} \mathrm{C}$ for $16 \mathrm{~h}$. The peptide fragments were extracted twice with $50 \mu \mathrm{L} 50 \%$ ACN/ $0.1 \%$ TFA. After removal of ACN by centrifugation in a vacuum centrifuge, the peptides were concentrated using $\mathrm{C}_{18}$ Zip-Tip (Millipore) and extracted with 5-10 $\mu \mathrm{L} 100 \%$ ACN and directly spotted on the sample plate of a MALDI-TOF-MS, mass spectra were then collected for PMF. The masses of peptide fragments were analyzed by MALDI-TOF at the core-facility laboratory of the Institute of Biological Chemistry, Academia Sinica using a dedicated Q-Tof UltimaTM MALDI instrument (Micromass, Manchester, UK).

\subsection{Protein identification by bioinformatic databases search and mass comparison}

Peptide masses and molecular masses were used to search NCBI databases with MASCOT program (http://www.matrixscience.com) for detailed PMF. Search parameters in the program allowed for oxidation of methionine, carbamidomethylation of cysteine, one missed trypsin cleavage, and 0.1 Da of mass accuracy for each peptide mass was allowed.

\subsection{RNA preparation and RT-PCR}

Various batches of HD30 total RNA were isolated from the harvest on CDC plates at appropriate time intervals under oxidative stress $\left(20 \% \mathrm{O}_{2}\right)$ using RNeasy mini kit (Qiagen). Subsequently, RNA $(500 \mathrm{ng})$ from each sample was reversetranscribed and PCR was performed using Superscript One-step RT-PCR kit (Invitrogen). One PCR cycle comprised: $94^{\circ} \mathrm{C}$ for $15 \mathrm{~s}, 55^{\circ} \mathrm{C}$ for $30 \mathrm{~s}$ and $72^{\circ} \mathrm{C}$ for $1 \mathrm{~min}$. The total cycle numbers were 35 with a final elongation step of $7 \mathrm{~min}$ at $72^{\circ} \mathrm{C}$. Primer sequences were designed as follows: for urease accessory protein E (UreE): 5'-CATATGATCATAGAGCGTTTAATG-3' and 5'-CTCGAGTTTCATGACCACTT TAAA-3'; AhpC: 5'-CCATATGTTAGTTACAAAACTTGCC-3' and 5'-CTCGAGAAGCTTAATGGAATTTTC-3'; and UreB: 5'-CATATGAAAAAGATTAGCAGAAAA-3' and 5'-GTGCC ATCAGCAGGACCAGTTCCG-3'. PCR products (521 bp for UreE , $601 \mathrm{bp}$ for AhpC) [21] were run on 1.5\% agarose gel and stained with $0.4 \mu \mathrm{g} / \mathrm{mL}$ ethidium bromide. Stained bands were visualized under UV light and photographed with a camera (Nikon E4500).

\section{Results}

\subsection{Urease activity of various $\boldsymbol{H}$. pylori strains under oxidative stress}

H. pylori strains from the patients of duodenal ulcer and gastric cancer were assayed for urease activity under oxidative stress. Figure $1 \mathrm{~A}$ illustrates the reduction of urease activity at a time interval of $0-36 \mathrm{~h}$ after exposure to $20 \% \mathrm{O}_{2}$. The urease activities of the different strains of $H$. pylori showed a time-dependent reduction and were completely abrogated after $32 \mathrm{~h}$. We also compared the difference

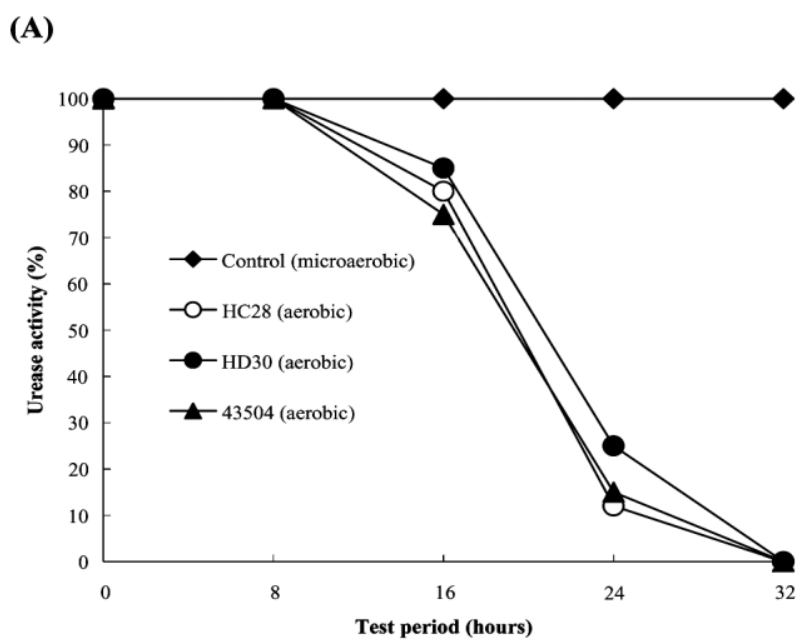

(B)
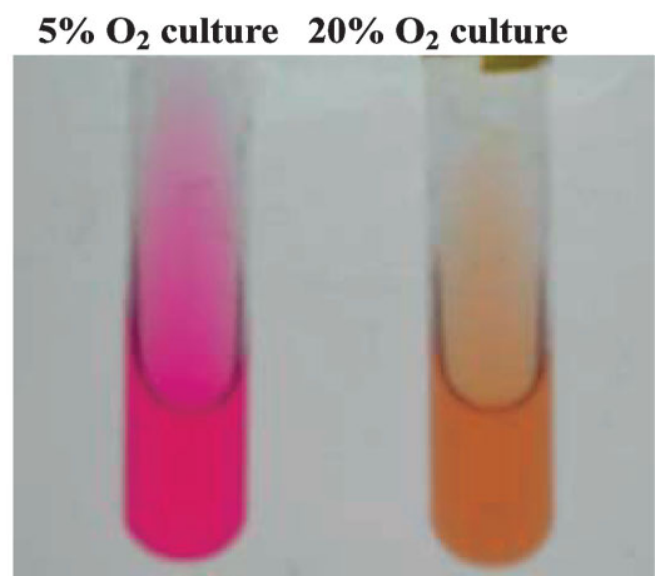

Figure 1. The reduction of urease activity in $\mathrm{H}$. pylori under oxidative stress. (A) The reduction of urease activity in different $H$. pylori strains was analyzed under oxidative stress $\left(20 \% \mathrm{O}_{2}\right)$. The time-course measurements of the urease activity were monitored by chemiluminescence method as described in the Materials and methods. Two clinical isolates ( $\mathrm{HC} 28, \mathrm{HD} 30)$ and one standard strain (ATCC 43504) of H. pylori were tested. Samples grown under microaerobic condition $\left(5 \% \mathrm{O}_{2}\right)$ were used as control. All data shown are means of triplicates from a representative experiment. (B) The rapid urease test kit (CLO ${ }^{\circledR}$ from Biostar) was used to compare urease activity of $\mathrm{H}$. pylori under normal $\left(5 \% \mathrm{O}_{2}\right)$ and oxidative stress $\left(20 \% \mathrm{O}_{2}\right)$ for $36 \mathrm{~h}$. The strong pink color in the left tube is due to the generation of ammonia from urea by urease in the absence of oxidative stress. 
between normal cells and oxidative-stress cells using a rapid urease test kit $\left(\mathrm{CLO}^{\circledR}\right.$, Biostar) (Fig. 1B). H. pylori grown under microaerophilic condition $\left(5 \% \mathrm{O}_{2}\right)$ still possessed active urease, allowing it to hydrolyze urea to ammonia which changed the color of the gel medium from yellow to pink. However, no visible changes were noted by the bacteria grown under $20 \% \mathrm{O}_{2}$.

\subsection{Subculture onto fresh CDC plates for proliferation test of $H$. pylori at $20 \% \mathrm{O}_{2}$}

A previous study has shown that $H$. pylori can transform from a bacillary to a coccoid form under oxygen tension [17]. These stress tests were usually conducted for only a short term (shorter than $22 \mathrm{~h}$ ) so that the results were insufficient to predict the actual survival and proliferation of $H$. pylori under long-term aerobic condition. Therefore, we incubated H. pylori strains (HD30 and HC28) continuously under atmospheric oxygen for 4, 8, 16, and $24 \mathrm{~h}$. We then subcultured them on fresh CDC plates for 2 days and measured the CFU on the plates. The results were shown in Fig. 2A, clearly indicating that the growth rates of $H$. pylori were greatly decreased under atmospheric oxygen for longer than $4 \mathrm{~h}$, and the proliferative abilities of HC28 and HD30 were reduced to one half of normal $H$. pylori after 16 and $8 \mathrm{~h}$, respectively. When $H$. pylori was incubated under oxidative stress for longer than $32 \mathrm{~h}$, it completely lost its proliferative activity on fresh culture plates (Fig. 2B).

\subsection{2-DE analysis of protein expression profiles of $H$. pylori under oxidative stress}

Global protein-expression profiles of two $H$. pylori strains (HD30 and HC28) under normal (5\%) and high oxygen tension $(20 \%)$ were analyzed using high-resolution 2-DE. The $\mathrm{p} I$ range for the first-dimension IEF strips was 3-10 and the second-dimension SDS-PAGE was run at $15 \%$ polyacrylamide gel (Fig. 3A-D). The 2-DE profiles of $H$. pylori grown under normal or hyperoxia conditions still exhibited more than 50 distinct spots between masses 14 and $96 \mathrm{kDa}$ and $\mathrm{p} I$ 3 and 9 range by image analysis. In this report we focused on proteins of more than $14 \mathrm{kDa}$ even though it is possible to detect low-molecular-weight (LMW) proteins with new ProteinChip technology [24]. The most abundant proteins locate at a zone with molecular weights $\left(M_{\mathrm{r}}\right)$ of 50000-95000 and pI of 4-6 (enclosed by a square block in Fig. 3). It is also noteworthy that $H$. pylori contains many protein isoforms, which may be due to inherent allelic or non-allelic polymorphism. Thus, protein isoforms typically differ slightly in their molecular masses and $\mathrm{pI}$. Isoforms present themselves as a series of spots that show numerous closely spaced spots in 2-DE profiles. Here we identified 11 differentially expressed protein spots under normal and high oxygen tension. Most notably and reproducibly, we found two protein spot areas (spots 1-3) with apparently reduced expression (enclosed by square blocks in Fig. 3 and highlighted by
(A)

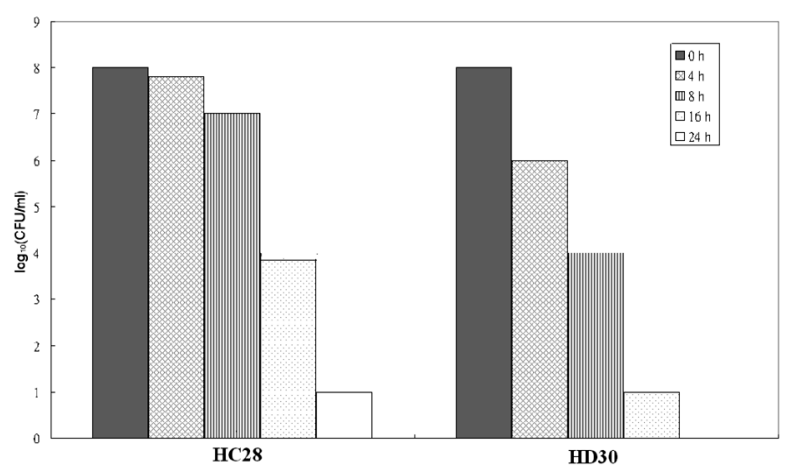

(B)

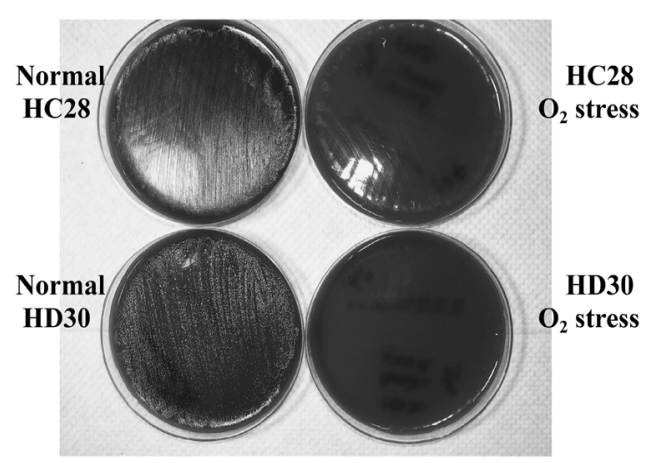

Figure 2. Proliferation potential of $H$. pylori cultured under atmospheric oxygen $\left(20 \% \mathrm{O}_{2}\right.$ ). (A) Clinical strains of $\mathrm{HC} 28$ (from the biopsy of gastric cancer) and HD30 (from the biopsy of duodenal ulcer) cultured under $5 \%$ oxygen were transferred to normal atmospheric condition ( $20 \%$ oxygen) and cultured continuously for 4-24 $\mathrm{h}$. Samples were then removed at each fixed time point, suspended in PBS and subcultured to fresh CDC plates. Experimental details were as described in the Materials and methods. The number of living cells was determined and represented as CFU. Data shown in Log (CFU/mL) are means of triplicates from a representative experiment. (B) Proliferation potential of $H$. pylori cultured under normal and oxidative-stress conditions. The cell proliferation assay was conducted by subculturing each test strain after 32-h stress treatment to fresh CDC plates for 2 days. It is evident that all cells are unculturable under oxidative stress (two plates on the right).

image analysis in Fig. 4). They were further analyzed by ingel spot digestion coupled with MALDI-MS and bioinformatic database search and PMF to confirm their identities (Table 1).

\subsection{RT-PCR analysis on $H$. pylori mRNA to monitor the transcription levels of AhpC and UreE genes induced by oxidative stress}

Among the 11 potential protein targets showing a differentially expressed pattern under oxygen stress, the most notable change was the reduced expression of two proteins, UreE (spot 1) and AhpC (spots 2 and 3) as shown in 2-DE. Con- 
(A)

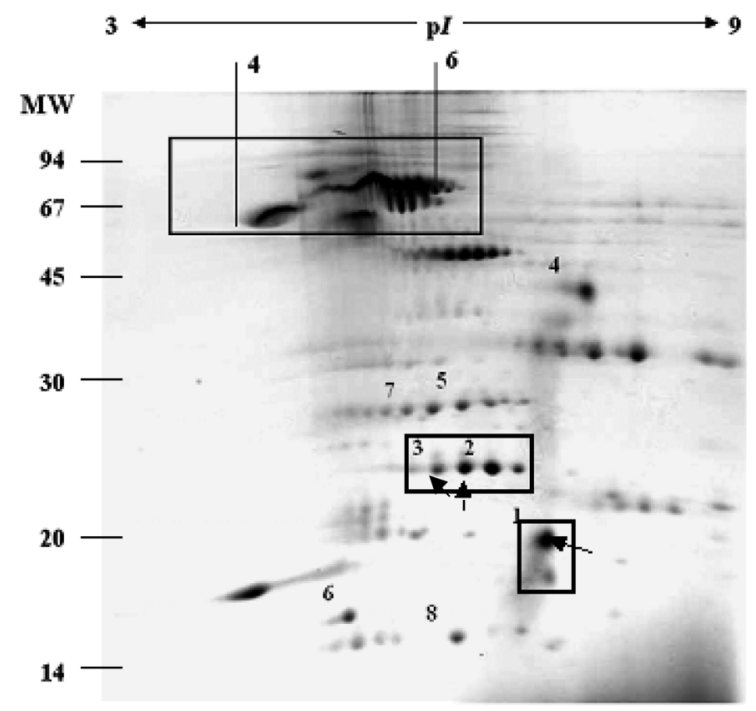

(B)

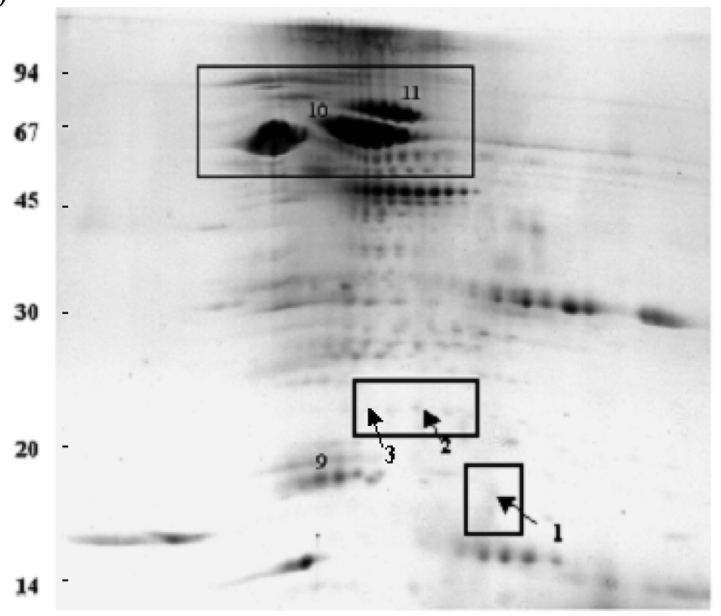

(C)

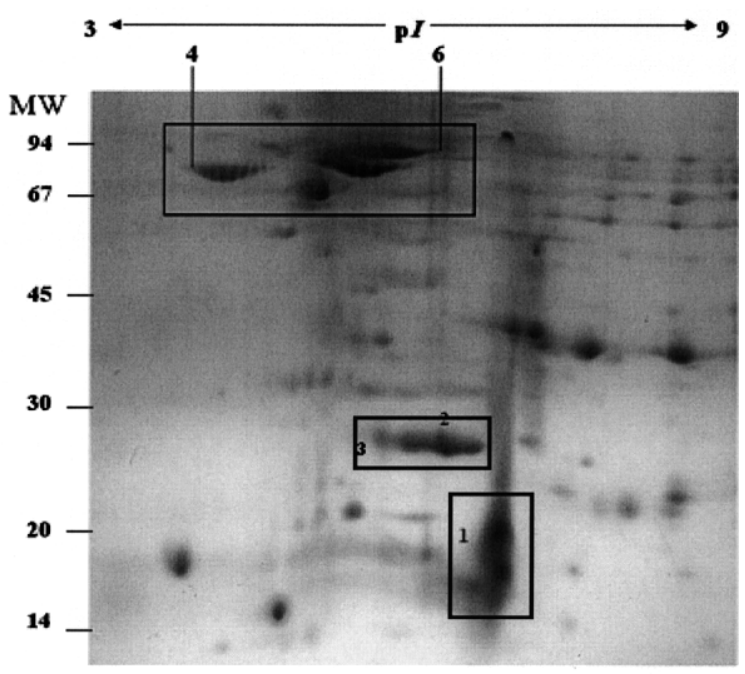

(D)

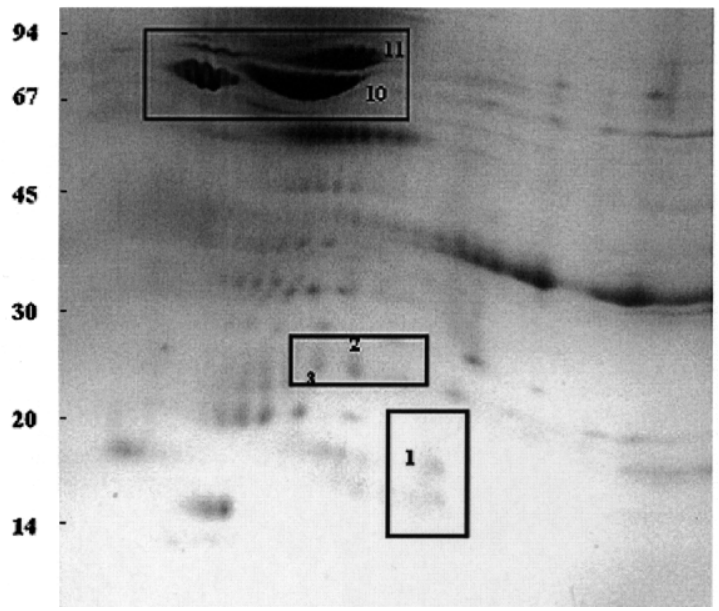

Figure 3. Comparative 2-DE patterns of H. pylori cultured under normal and oxidative-stress conditions. About $300 \mu \mathrm{g}$ total protein from lysates of $H$. pylori cells was loaded on IPG gel strips $(\mathrm{pH} 3-10,18 \mathrm{~cm})$. The IPG strips were rehydrated and, after IEF, subjected to 2-DE. A concurrent run of six standard marker proteins with their molecular masses is shown on the left lane. (A, B) 2-DE protein profiles of HD30 (H. pylori strain isolated from duodenal ulcer biopsy) under normal (A) and oxidative-stress (B) conditions. Protein spots marked by nos. 1-11 on the maps were found to be differentially expressed; these were further identified by MALDI-TOF. (C, D) 2-DE protein profiles of HG28 (H. pylori strain isolated from gastric cancer biopsy) under normal (C) and oxidative-stress (D) conditions. Protein spots marked by numbers [same as those designated in $(A)$ and $(B)$ ] on the maps were found to be differentially expressed, and were further identified by MALDI-TOF (Table 1). Note that the same protein alterations, especially protein spots $1-3$, are consistently observed for the two different pathological strains in $(A, B)$ and $(C, D)$.

cerning the crucial roles played by these two proteins in antioxidative stress and activation of urease, we further determined whether their reduction was manifested at the transcriptional level. As shown in Fig. 5, time-dependent reduction of AhpC and UreE mRNA level was clearly observed after a period of exposure to oxidative stress. The transcription of these two genes was initially repressed after about $8 \mathrm{~h}$, and fully inhibited at $24 \mathrm{~h}$, corroborating the result of proteomic analysis.

\section{Discussion}

H. pylori is a microaerophilic bacterium. Under an optimal oxygen concentration (5-10\%), most $H$. pylori strains grow in bacillary forms, whereas they transform to coccoid forms under oxidative-stress conditions. Our results showing the predominating coccoid form of $H$. pylori under higher oxygen concentration are in agreement with previous reports $[16,17]$. Recently, Park et al. [23] demonstrated that repressed 
(A)

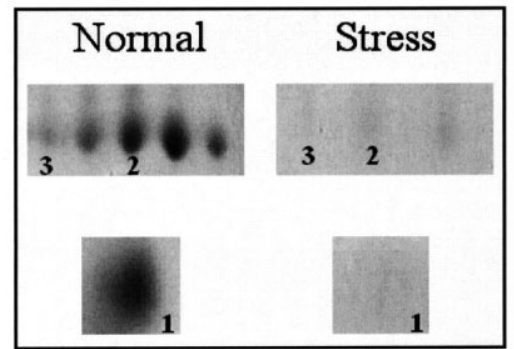

(B)

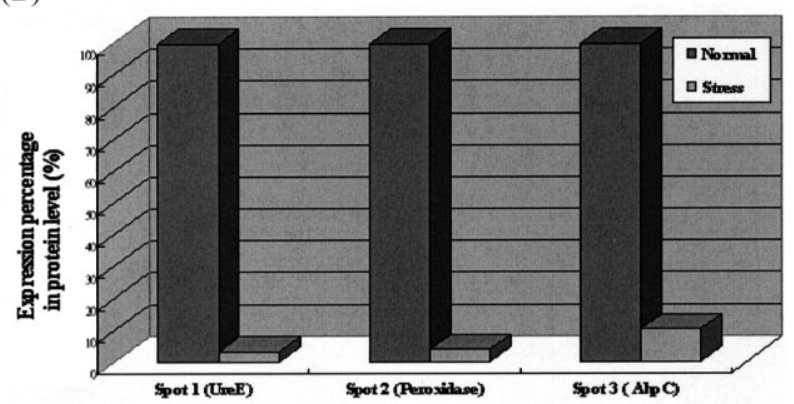

Figure 4. Image quantitative analysis of AhpC and UreE. (A) Highlight profiles of protein spots (spots 1-3 in Fig. 3 ) as revealed using a high-resolution scanner. Intensity levels were normalized between gels as a proportion of the total protein intensity detected for the entire gel. The displayed protein spots on (A) were then quantitatively analyzed using ImageMaster ${ }^{\mathrm{TM}}$ software and are shown in bar representation (B). The expressed amounts of the three protein spots (spots 1-3) in HD30 were decreased 33-, 25- and 10-fold, respectively, for spots 1-3 under oxidative stress. The three spots were also further identified by MS, as shown in Table 1. Spot 1: UreE; spot 2: peroxidase (an isoform of AhpC); and spot 3: AhpC.

growth of the coccoid forms of $H$. pylori cultured under nonoptimal $\mathrm{O}_{2}$ tension is presumably due to oxidative injury of proteins and DNA by an increased generation of hydroxyl radicals as compared with that of the bacillary form. Moreover, they found that urease activity and the number of CFU decreased markedly under both aerobic and anaerobic culture conditions. We have also observed that the proliferation and urease activity showed a significant decrease when $H$. pylori suffered from high oxygen stress (20\%), In our results, the urease activity remained normal for the first $8 \mathrm{~h}$; however, prolonged oxidative stress apparently inhibited urease activity after $16 \mathrm{~h}$. The activity decreased to about $50 \%$ at $20 \mathrm{~h}$, and no activity was detected after $32 \mathrm{~h}$ (see Fig. 1A, B). Although previous studies have proposed that urease can be inhibited under oxidative stress $[23,25]$, we have found that this enzyme can maintain activity for $8-16 \mathrm{~h}$ but not for longer than 1 day if $H$. pylori are continuously exposed to high oxygen tension. Since urease is essential for H. pylori to survive in the acidic stomach, the observed phenomenon might be related to the slow growing or even uncultivable characteristics in the coccoid form (see Fig. 2A, B).

Through a proteomic approach, we have identified 11 proteins that were differentially expressed under oxidative stress (Fig. 3A-D). In our bioinformatic database search and PMF coupled with sequence comparison, the most notable and significant changes lie in two proteins, AhpC and UreE. AhpC has been demonstrated to be a major anti-oxidant enzyme to prevent $H$. pylori from severe damage by "oxygen shock" $[18,19,25,26]$, and UreE has been reported to be a Nisequestering protein, which is an accessory protein and a nickel-metallochaperone for urease activity [7, 27-29]. Both proteins have been identified and revealed by proteomic analysis for the first time to be greatly inhibited at the protein expression level under oxidative stress. Because UreE and AhpC were consistently reduced in both cancer and ulcer strains, we have further corroborated the proteomic analysis by analyzing alterations of mRNA levels of these two genes. As shown by RT-PCR (Fig. 4), both genes displayed a timedependent decrease of mRNA under high oxygen tension.

Table 1. Mass identification of 11 differentially expressed protein spots under oxidative stress

\begin{tabular}{|c|c|c|c|c|c|c|}
\hline \multirow[t]{2}{*}{ Spot } & \multirow{2}{*}{$\begin{array}{l}\text { Protein identified } \\
\text { (most probable candidate) }\end{array}$} & \multirow{2}{*}{$\begin{array}{l}\text { NCBInr } \\
\text { accession } \\
\text { no. }\end{array}$} & \multicolumn{2}{|c|}{ Predicted mol. mass } & \multirow[t]{2}{*}{ Score } & \multirow[t]{2}{*}{ Match } \\
\hline & & & (kDa) & $\mathrm{p} /$ & & \\
\hline $1^{\text {a) }}$ & UreE accessory protein & B41834 & 19 & 8.56 & 52 & 4 \\
\hline $2^{\mathrm{b})}$ & Probable peroxidase & M71801 & 22 & 5.98 & 52 & 7 \\
\hline $3^{\text {a) }}$ & Alkylhydroperoxide reductase & C64715 & 22 & 5.88 & 55 & 5 \\
\hline 4 & HP0660 (hypothetical protein) & D64602 & 39 & 8.34 & 55 & 5 \\
\hline 5 & Orotidin 5'-phosphate decarboxylase & $\mathrm{E} 64520$ & 25 & 5.16 & 68 & 6 \\
\hline 6 & Riboflavin synthase $\beta$-chain & D71982 & 17 & 5.23 & 48 & 5 \\
\hline 7 & Adenylate kinase & B64597 & 21 & 5.27 & 35 & 4 \\
\hline 8 & Chemotaxis protein (CheY) & C64653 & 14 & 5.26 & 42 & 4 \\
\hline 9 & NapA protein & C64550 & 17 & 5.59 & 52 & 4 \\
\hline 10 & HSP60 (GroEL) & S36237 & 59 & 5.55 & 60 & 8 \\
\hline $11^{\text {a) }}$ & Urease $\beta$-subunit & URKCBP & 62 & 5.64 & 75 & 8 \\
\hline
\end{tabular}

a) Protein expression levels analyzed by RT-PCR.

b) This protein may be one of the isoforms of AhpC because its amino acid sequence is found to be $98 \%$ homologous to AhpC. 


\section{Oxidative stress $\left(\mathrm{O}_{2}\right)$}

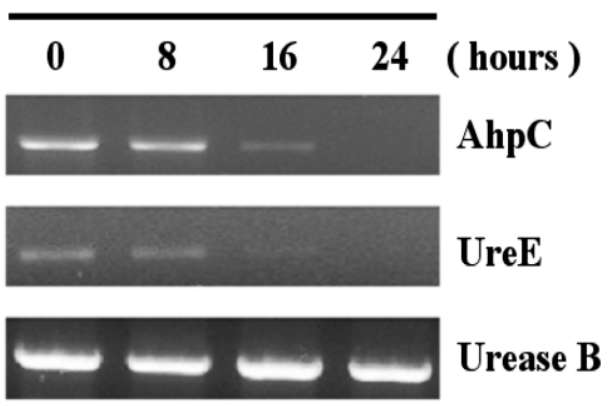

Figure 5. RT-PCR analysis on mRNA transcription corresponding to $\mathrm{AhpC}$ and UreE genes in H. pylori. Different batches of HD30 total RNA were isolated from the harvest on CDC plates at appropriate time intervals under oxidative stress $\left(20 \% \mathrm{O}_{2}\right)$ using RNeasy mini kit (Qiagen). Subsequently, RNA (500 ng) from each sample was reverse-transcribed and PCR was performed using Superscript One-step RT-PCR kit (Invitrogen). PCR products were run on $1.5 \%$ agarose gel and stained with $0.4 \mu \mathrm{g} / \mathrm{mL}$ ethidium bromide. Stained bands were visualized under UV light and photographed with a camera (Nikon E4500). UreB was used as control gene for the quantification of RT-PCR products. The numbers $(0,8,16,24)$ indicate culture times in hours of HD30 under oxidative stress.

Thus, changes in mRNA transcription under oxidative stress correlate well with the protein change by proteomic analysis. Our data, which show that the amount of AhpC was inhibited at both transcriptional and translational levels, rather than induced under long-term oxidative stress (Figs. 3, 4), are consistent with fact that H. pylori is difficult to isolate from the natural environment. It is conceivable that repression of UreE and AhpC may be two major factors contributing to the inhibitory effect on urease and proliferative potential of $H$. pylori under severe, long-term oxidative stress. These two proteins could also nicely account for the observations shown in Figs. 1A, B, and 2A, B. Therefore, we propose that under long-term oxygen-tension condition, the repression of UreE is a critical factor for the decline of urease activity, and that the inhibition of AhpC results in the absence of anti-oxidative ability, leading to the loss of survival and proliferation potential. In summary, we have identified two protein targets, UreE and AhpC, which show time-dependent repression at the protein and mRNA levels under oxidative stress, and may be listed as potential targets for the development of therapeutic agents against $H$. pylori.

This work was supported in part by a grant from the National Science Council (NSC 93-2311-B-002-033 to S.-H. Chiou) and a grant from National Taiwan University Hospital (to M.-S. Wu and J.-T. Lin). We thank Hwei-Yuan Chang for her preparing and providing the clinical isolates of $\mathrm{H}$. pylori for this study.

\section{References}

[1] Marshell, B. J., Warren, J. R., Lancet 1984, 1, 1311-1315.

[2] Hopkins, R. J., Girardi, L. S., Turney, E. A., Gastroenterology 1996, 110, 1244-1252.

[3] Kreiss, C., Blum, A. L., Malfertheiner, P., Curr. Opin. Gastroenterol. 1995, 11, 25-31.

[4] Petersen, A. M., Krogfelt, K. A., FEMS Immunol. Med. Microbiol. 2003, 36, 117-126.

[5] Suerbaum, S., Michetti, P., N. Engl. J. Med. 2002, 347, 11751186.

[6] Matsubara, S., Shibata, H., Ishikawa, F., Yokokura, T. et al., Biochem. Biophys. Res. Commun. 2003, 310, 715-719.

[7] Mulrooney, S. B., Hausinger, R. P., FEMS Microbiol. Rev. 2003, 27, 239-261.

[8] Ohta, T., Shibata, H., Kawamori, T., limuro, M. et al., Biochem. Biophys. Res. Commun. 2001, 285, 728-733.

[9] Tsujii, M., Kawano, S., Tsuji, S., Fusamoto, H. et al., Gastroenterology 1992, 102, 1881-1888.

[10] Sakagami, T., Vella, J., Dixon, M. F., O'Rourke, J. et al., Infect. Immun. 1997, 65, 3310-3316.

[11] Blaser, M. J., Biomed. J. 1998, 316, 1507-1510.

[12] Yeo, M., Park, H. K., Kim, D. K., Cho, S. W. et al., Proteomics 2004, 4, 3335-3342.

[13] de Vries, N., van Ark, E. M., Stoof, J., Kuipers, E. J. et al., FEMS Immunol. Med. Microbiol. 2003, 38, 45-51.

[14] Matsukawa, Y., Asai, Y., Kitamura, N., Sawada, S. et al., Med. Hypotheses 2005, 64, 41-43.

[15] Naito, Y., Yoshikawa, T., Free Radic. Biol. Med. 2002, 33, 323336.

[16] Rabelo-Goncalves, E. M., Nishimura, N. F., Zeitune, J. M., Mem. Inst. Oswaldo Cruz. 2002, 97, 1201-1206.

[17] Nakamura, A., Park, A. M., Nagata, K., Sato, E. F. et al., Free Radic. Biol. Med. 2000, 28, 1611-1618.

[18] Olczak, A. A., Olson, J. W., Maier, R. J., J. Bacteriol. 2002, 184, 3186-3193.

[19] Comtois, S. L., Gidley, M. D., Kelly, D. J., Microbiology 2003, 149, 121-129.

[20] Wang, G., Maier, R. J., Infect. Immun. 2004, 72, 1391-1396.

[21] Tomb,J. F., White, O., Kerlavage, A. R., Clayton, R. A. et al., Nature 1997, 388, 539-547.

[22] Baek, H. Y., Lim, J. W., Kim, H., Kim, J. M. et al., Biochem. J. 2004, 379, 291-299.

[23] Park, A. M., Li, Q., Nagata, K., Tamura, T. et al., Free Radic. Biol. Med. 2004, 36, 1126-1133.

[24] Hynes, S. O., McGuire, J., Falt, T., Wadström, T., Proteomics 2003, 3, 273-278.

[25] Barnard, F. M., Loughlin, M. F., Fainberg, H. P., Messenger, M. P. et al., Mol. Microbiol. 2004, 51, 15-32.

[26] Lundstrom, A. M., Sundaeus, V., Bolin, I., Helicobacter 2001, $6,44-54$.

[27] Soriano, A., Colpas, G. J., Hausinger, R. P., Biochemistry 2000, 39, 12435-12440.

[28] Benoit, S., Maier, R. J., J. Bacteriol. 2003, 185, 4787-4795.

[29] Won, H. S., Lee, Y. H., Kim, J. H., Shin, I. S. et al., J Biol Chem. 2004, 279, 17466-17472. 